\title{
The Rational Analytical Approach to Decision-Making: An Adequate Strategy for Military Commanders?
}

\section{Rolf I. Roth ${ }^{*}$}

Decision-making is the first step in implementing human will, and is therefore a prime human factor in warfare. Military education, training, and exercises are all focused on aspects of decision-making. ${ }^{1}$ British Military Doctrine (BMD) states that the "exercise of command is primarily concerned with the decision making process." ${ }^{2}$ British Army doctrine emphasizes that it requires "good judgment and initiative" to know when a decision is needed. ${ }^{3}$

Most factors influencing decision-making are reflected in how military forces train and exercise. Time, stress, fatigue, information demand, information overload, noise, and sleep deprivation, to mention some, are part of the training scenario. Methods for managing decision-making under such conditions are regularly taught to military forces. Rational analytical decision-making, based on a comparison of quantitative options, is the preferred decision method, and is primarily done by what is known as the estimate process. Factors that are closely linked to the personality of the commander, like intuition and creativity, are generally emphasized in doctrine as being important. However, these aspects are rarely given any significance in the education, training, and exercise environment, as they are impossible to teach, but they are regarded as crucial in wartime, and are expected to materialize when they are most needed.

Thorough training and drilling in analytical decision-making may leave the military officer sounding prepared to make excellent decisions, but is there judgment behind the language? New research has rediscovered old knowledge about the possibilities of the human mind. Individuals as well as organizations can benefit from this research. However, it might require a reevaluation in the area of decision-making, particularly regarding the almost total reliance on the rational analytical approach. The business world has started looking for other attributes in a leader than rational analytical skills. Expressions like "the articulate incompetent" have been used about a particular business type that is "full of good ideas immaculately presented, but that lack substance, and don't work." Henry Mintzberg has discussed corporate planning and the inadequacies of the rational and analytical process for the business world. "A good deal of corporate planning ... is like a ritual rain dance. It has no effect on the weather that follows, but those who engage in it think it does. ... Moreover, much of the advice

Commander Rolf I. Roth is an Officer in the Royal Norwegian Navy.

1 Gen. C.C. Krulak, "Cultivating Intuitive Decision-making," Marine Corps Gazette (May 1999):18-22.

2 British Military Doctrine (Army Code 71451), 4-17.

3 Army Doctrine Publication, v. 2, Command (Army Code 71564), 2-9.

4 Guy Claxton, Hare Brain Tortoise Mind (London: Fourth Estate, 1998), 210.

5 Henry Mintzberg, The Rise and Fall of Strategic Planning (New York: Prentice Hall, 1994), quoted in Claxton, Hare Brain, 211. 
related to corporate planning is directed at improving the dancing, not the weather." This is not to suggest that the rational analytical process of planning and decisionmaking has become obsolete. It is still an important and necessary tool, but new research shows that it can be supplemented by other strategies that explore the resources of the unconscious mind.

These strategies are not new, but were somehow 'lost' during the industrial and technical revolution. A number of factors influence decision-making, including factors that are tightly linked to the personality of the decision-maker. Some are well known, while individuals are not consciously aware of some others, but even if they are unconscious these factors can have an influence on conscious life. Shakespeare wrote about the inability to see the source of one's own experience, or to comprehend its true meaning ${ }^{7}$ :

In sooth, I know not why I am so sad:

It wearies me; you say it wearies you;

But how I caught it, found it, or came by it, What stuff 'tis made of, whereof it is born,

I am to learn;

And such a want-wit sadness makes of me,

That I have much ado to know myself.

St. Thomas Aquinas noted, back in the thirteenth century, that "there are processes in the soul of which we are not immediately aware." 9 The need for greater self-awareness, whether of the soul or elsewhere, can also be related to the different aspects of military command. In learning to reach greater self-awareness, it can be useful to examine the origins, nature, methods, and limits of human knowledge. Today, cognitive science is the name given to the cluster of disciplines that studies the human mind. ${ }^{10}$

Guy Claxton blames Descartes for the lost understanding of the link between the conscious and unconscious mind. ${ }^{11}$ Humans have, according to Claxton, generally lost the ability to exploit the full capacity of the mind. Descartes, in his work Meditations, 'proved' that no such thing as the intelligent unconscious existed. In a similar fashion, the Newtonian paradigm, with its "Majestic Clockwork" metaphor, strongly influenced

${ }^{6}$ Brian Quinn, quoted in Claxton, Hare Brain, 211.

7 Claxton, Hare Brain, 204.

${ }^{8}$ William Shakespeare, The Merchant of Venice, Act I, scene 1, in William Shakespeare: The Complete Works (London: Michael O’Mara Books Limited, 1992), 177.

9 Claxton, Hare Brain, 204.

${ }^{10}$ A.S. Reber, The Penguin Dictionary of Psychology (London: Penguin Group, 1985), 130.

${ }^{11}$ Claxton, Hare Brain, 205. 
the Enlightenment and the Scientific Revolution in Western philosophy. ${ }^{12}$ Much was gained from focusing on optimal solutions by dividing problems into manageable subproblems, then solving complex problems by putting all the sub-problems together to arrive at great concepts.

Today, new research in cognitive science has shed light on the workings of the unconscious, challenging some of the accepted 'facts' of rational analysis as the only tool for solving complex problems. Throughout time, authors have touched on the same ideas - like Shakespeare, searching for some undefined qualities within the mind. Among these are military authors, like Major-General J. F. C. Fuller, who talked about that special, indefinable something that can produce startling and, frequently, incomprehensible results, because of some "power" at the commanders' disposal. He wrote, "That some explanation exists cannot be doubted, but so far science has not revealed it, though the psychology is working towards its fringe."13

This essay will argue that, among the various factors that can influence decisionmaking, there are some that are deserving new attention as a result of recent research on how decisions actually are made. Of particular interest is the recent focus by cognitive scientists on what is referred to as the unconscious intelligence of the mind. ${ }^{14}$ To look at the new conception of the unconscious, it is necessary to look closer at factors like perception, intuition, and creativity. These factors are often associated with irrational and illogical behavior, and are frequently seen as a cause for human error in decision-making. The military seeks to eliminate this risk by applying a strategy of rational analysis to decision-making. Several authors have given attention to the idea that the military has lost some of the 'art' in military command through this approach. ${ }^{15}$ New research supports the idea of putting more emphasis on intuition. Insight into this area can bring added understanding and value to military command.

Increased self-awareness and insight into the workings of our deeper mind are the ways to gain a better understanding of this process. This paper will argue that there might be more benefit gained from exploiting the human aspects of decision-making than from eliminating them. By looking into "The Undermind Society," it is possible to discover ways of learning that nurture our creativity and intuition. A renewed atten-

${ }^{12}$ R.P. Pellegrini, The Links between Science and Philosophy and Military Theory: Understanding the Past: Implications for the Future (Maxwell AFB, AL: Air University Press, 1997), 12; quoted in D.T. Gyllensporre, "Decision Navigation: Coping with 21 ${ }^{\text {st }}$-Century Challenges in Tactical Decision-making," Military Review (Sept-Oct 2003): 22.

${ }^{13}$ Maj.-Gen. J.F.C. Fuller, The Foundation of the Science of War (London: Hutchinson, 1926), 98-99.

${ }^{14}$ Claxton, Hare Brain, 7.

${ }^{15}$ Brigadier G.L. Kerr, "Intuitive Decision-Making at the Operational Level of Command," British Army Review 108 (1994): 5-13.

${ }^{16}$ Claxton, Hare Brain, 201-226. Claxton uses the term "the undermind" in the sense of the intelligent unconscious. 
tion to the learning curriculum might be necessary in order to exploit these capabilities that are traditionally not the focus of military education. ${ }^{17}$

To do this, a closer look must be given to perception, intuition, creativity, and the connection between the conscious and the unconscious mind. The various causes of human error, and their implications for decision-making, will be discussed, as will military command with regard to information and uncertainty in decision-making. The main decision-making models will be analyzed to evaluate their significance as decision-making strategies. Theories from cognitive science will then be used to show how the military decision-making strategy can be supplemented by new research to develop it further and enhance its capability. The discussion will develop based on the understanding of decision-making found in British military doctrine.

Decision-making is about making choices between alternatives. Some decisions are more complex than others, and it can be a multifaceted process that can offer many possible approaches to reaching a decision. Many factors influence decision-making. Our perception is the medium through which we approach sources and take in different types of information. The way we let intuition and creativity influence our decisionmaking strategy is likely to vary from person to person. Each of these factors can also give rise to biases that form and influence our decision-making, and might well be the cause for human error in decision-making.

Perception has been described as all those processes that give coherence and unity to sensory input. Perception can be a synthesis or fusion of the elements of sensation, but it can also be an awareness of the truth of something. The last sense is primarily non-technical and connotes a kind of implicit, intuitive insight. In essence, the concept of perception is far-reaching, and begins with the recognition of the fact that what is perceived is not only determined by physical stimulation but also, and more important, is an organized complex, depending on a host of other factors. ${ }^{18}$ Robbins calls it "a process by which individuals organize and interpret their sensory impressions in order to give meaning to their environment." ${ }^{, 19}$ Therefore, one could argue that people's decision-making is based upon their perception of reality, and not on the objective fact of what reality is. This makes perception one of the important factors in decision-making.

Intuition is described in Chambers' dictionary as "the power of the mind by which it immediately perceives the truth of things, without reasoning or analysis." Many might consider intuition as 'good guesses,' hunches, or hypotheses thrown up by the unconscious. The unconscious mind may offer an overall 'take' on a situation as an inkling or an image. "Behind the scenes, the 'undermind' may have integrated into this tangible prompt a host of different considerations, including analogies to past experiences and aspects of the present situation, of which the conscious mind may not have

${ }^{17}$ Col. C.T. Rogers, "Intuition: An Imperative of Command," Military Review (March 1994): 48-50.

${ }_{18}^{18}$ Reber, Penguin Dictionary of Psychology, 527.

${ }^{19}$ S.P. Robbins, Organizational Behavior: Concepts, Controversies, and Applications (Englewood Cliffs, NJ: Prentice-Hall, 1993), 135. 
even been aware." ${ }^{20}$ Intuition has been described as a mode of understanding or knowing characterized as direct and immediate and occurring without conscious thought or judgment. It is a response to subtle cues and relationships apprehended implicitly and unconsciously. This hints at a number of difficult but fascinating problems in the study of human behavior when confronted with complex situations. ${ }^{21}$

Creativity is a term that refers to mental processes that lead to solutions, ideas, conceptualization, artistic forms, theories, or products that are unique and novel. ${ }^{22}$ The decision-maker needs creativity to produce novel and useful ideas. Creativity both helps the decision-maker to identify all viable alternatives and to think about a problem in innovative or divergent ways. Studies suggest that most people have a potential for creativity. However, it is necessary to learn how to unleash it. Creative ideas develop from a combination of knowledge, the ability to produce analogies, and the courage and drive to work the potential idea into an actuality. ${ }^{23}$ Today, cognitive science takes interest in what is referred to as the "fringe of the mind," and the idea first offered in 1890 by William James, who wrote about the "reinstatement of the vague" - the ability to catch ideas that are not yet fully formed. Creative people are more capable of catching "the gleam of an idea as it flashes across the corner of their consciousness," and somehow manage to capture concepts as they appear from the unconscious. ${ }^{24}$

To come to grips with the unconscious mind, it is necessary to link it to the conscious. Descartes' legacy is the image of "the theater of consciousness," where the action of mental life takes place on a brightly illuminated stage. Here human intelligence, consciousness, and identity all come together, and everything that exists can be seen and known. ${ }^{25}$ Claxton turns this Cartesian image of the mind against itself by expanding the "theater" analogy. It is necessary to look at what happens behind the scenes, to understand that there is activity even when one consciously does not reflect on it. The visible appearance of the scene is not all there is. As in an actual theatrical production, "The visible performance presupposes an enormous amount of invisible apparatus and activity." 26 The unconscious intelligence is a term by which cognitive science gives the unconscious mind back its true value, and confirms that there is intelligent work going on "behind the scenes."

Having looked at some factors of the mind that can be difficult to define, there may be good reason why the military is concerned with their general influence. Human error is a factor in decision-making, and decision-making models have been developed

${ }^{20}$ Claxton, Hare Brain, 50.

${ }^{21}$ Reber, Penguin Dictionary of Psychology, 373.

${ }^{22}$ Reber, Penguin Dictionary of Psychology, 165.

${ }^{23}$ S.P. Robbins, Organizational Behavior, rev. ed. (Upper Saddle River, NJ: Prentice Hall, 2001), 133-34.

24 "What's the Big Idea?" The Observer, 22 September 2002 (comment on Guy Claxton's book Hare Brain Tortoise Mind).

${ }^{25}$ Claxton, Hare Brain, 222.

${ }^{26}$ Claxton, Hare Brain, 225. 
that seek to eliminate it. Still, it is a cause for concern, and much research has been done in the area of human bias and its effect.

Decision bias can be described as the concept of people making bad decisions because of a predisposition to do so. This could be a result of pre-existing conscious beliefs. The reasons can be many, and often include inherited tendencies, like over-reliance on more readily available (or apparently more reliable) data, or inaccurate use of base rates. The tendency not to take sample size into account and difficulty in reaching logical conclusions are other examples. ${ }^{27}$

There is substantial evidence that people have a tendency to underestimate the influence of external factors and underestimate the influence of internal or personal factors when we make judgment about the behavior of other people. This is referred to as fundamental attribution error. ${ }^{28}$ The tendency to see and hear selectively based on motivation, needs, experience, background, and other personal characteristics is called selective bias. In taking in and understanding information, people have a tendency to project their own interests and expectations into the information. We do not always see reality; instead, we interpret what we see and call it reality. ${ }^{29}$ Mauer argues that commanders' decisions are based on filtering information through the biases that affect their thinking, and down through history warnings have been ignored because of a particular commander's mindset. ${ }^{30}$ One example is the fact that, despite advance information, Stalin's mindset did not allow him to recognize the warnings from his allies that Hitler was planning a surprise attack on Russia in $1941 .^{31}$

Individuals have a limit for processing data. Research indicates that, on the average, when an individual is working with more than approximately seven pieces of information, the result will be information overload. ${ }^{32}$ This will in most cases result in lost information, and it is reasonable to assume that in this situation the information that gets lost could be important, since at this stage there no longer exists a working information management system. In order to avoid the danger of information overload, decision makers often rely on judgmental shortcuts, or heuristics, in decision-making. ${ }^{33}$ Availability and representativeness are two common categories of heuristics that both

${ }^{27}$ G.A. Klein, "Strategies of Decision Making," Military Review (May 1989): 56-64; and Claxton, Hare Brain, 37-38.

${ }^{28}$ Robbins, Organizational Behavior (1993), 140.

${ }^{29}$ Robbins, Organizational Behavior (2001), 287.

${ }^{30}$ M. Mauer, Coalition Command and Control, Key Consideration (Washington, D.C.: National Defense University, 1996), 66.

${ }^{31}$ Mauer, Coalition Command and Control, 66.

${ }^{32}$ G.A. Miller, "The Magical Number Seven, Plus or Minus Two: Some Limits on Our Capacity for Processing Information,” Psychological Review (March 1956): 81-97.

${ }^{33}$ A. Tversky and K. Kahneman, "Judgment under Uncertainty: Heuristics and Biases," Science (September 1974): 1124-31; and J.S. Hammond, R.L. Keeney, and H. Raiffa, "The Hidden Traps in Decision Making," Harvard Business Review (September-October 1998): 47-48. 
create bias in judgment. Another bias among decision-makers is the tendency to escalate commitment to a failing course of action. ${ }^{34}$

Availability bias is the tendency to base judgments on information that is readily available, while the representative heuristic comes into play in assessing the likelihood of an occurrence by drawing analogies and seeing identical situations in places where they do not exist. People tend to assess the likelihood of an occurrence by trying to match it with a pre-existing category. ${ }^{35}$ Escalation of commitment, by contrast, "is an increased commitment to a previous decision in spite of negative information." 36 This may be a result of trying to show consistency in the pursuit of a particular course of action. If it is felt that too much has already been invested into a project, it could become extremely difficult to cancel the project.

Cultural differences can be another explanation for different reactions in particular circumstances, and are often an issue in multinational coalitions. Confirmation bias describes the fact that humans are notorious for overvaluing information that supports their assumptions, and ignoring that which challenges their pre-conceptions. The last is called disconfirmation bias, and influences how we select types and sources of information.

According to Dr. Klein, researchers have identified more than two-dozen "heuristics or biases." However, many of the findings are linked to experiments under laboratory, not real-world, conditions. Several other studies show that the decision biases can be reduced when contextual factors are included. Experienced decision-makers are not subject to heuristics and biases when working in natural settings. Most poor decisions result from inadequate knowledge and expertise. ${ }^{37}$

As can be concluded from the argument above, human bias can be used as an argument for eliminating as much of the human factor as possible from the decisionmaking process. The human factor can undoubtedly play a large role in the outcome of a decision if a purely rational and analytical approach is not used. The USS Vincennes shooting down of an Iranian airliner in 1988 has been used as a prime example of human bias in decision-making that led to fatal consequences. According to Klein, the real cause was equipment failure, or equipment not adequately designed to allow the personnel in the operation room to comprehend and recognize the important bits of information that were present. By studying the incident, knowledge can be gained on the significance of error, human or otherwise.

The incident took place during the Iraq-Iran war, while the AEGIS Cruiser the USS Vincennes was engaged in surface action with Iranian gunboats. The situation is interesting from several perspectives, as it involves decision-making under time pressure during an episode that posed significant threat to those involved. Several pieces of

\footnotetext{
${ }^{34}$ Robbins, Organizational Behavior (2001), 139.

${ }^{35}$ Robbins, Organizational Behavior (2001), 140.

36 Ibid.

${ }^{37}$ Gary Klein, Sources of Power: How People Make Decisions (Cambridge, MA: MIT Press, 1998), 272-75.
} 
information were being handled at the same time, and the situation offered several possible different courses of action. This is emphasized by the fact that the situational awareness of the commander of the USS Vincennes, Capt. Rogers, was completely different from that of the commander of the USS Sides, which was operating in the same area.

The USS Vincennes had previous experience with hostile action by the Iranian air force. On 18 April 1988, two F-4s had committed what by the existing rules of engagement qualified as a hostile act by locking their target acquisition radar on the USS Vincennes. Capt. Rogers tried to understand how the pilots were thinking and what their intent was. He did not believe they would attack, and therefore did not allow himself to become provoked. Several pieces of information, coupled with past experience, led to his correct understanding of the situation. Capt. Rogers recognized a pattern that led him to a decision. The F-4s disengaged and returned to base. He would use the same strategy on the morning of 3 July 1988, when the USS Vincennes fired two missiles that shot down the Iranian Airbus 300, Iran Air Flight 655, but this time he was mistaken. $^{38}$

Iranian F-14s and F-4s were based at Bandar Abbas airport, from which Flight 655 took off. During the time before the fatal downing of the airliner, several incidents involving Iranian F-4s or F-14s and U.S. warships had taken place. In one instance, an F14 had broken off a direct route towards a U.S. cruiser after radio warnings, and after the cruiser had locked on to it with fire control radar. In another incident, an Iranian F4 had taken off from Bandar Abbas flying just below a commercial airliner in order to avoid radar detection. Iranian fighters were also known to have been transmitting signals to indicate that they were civilian aircraft. Rules of engagement had been adjusted to give commanders more freedom to defend themselves even before being fired upon. ${ }^{39}$ Under the circumstances, fighters flying attack profiles could be expected.

As Flight 655 took off from Bandar Abbas, the USS Vincennes was engaged in a surface action with Iranian gunboats and had to maneuver sharply while firing its gun. The USS Vincennes fired the missiles seven minutes after Flight 655 took off. A number of different pieces of information, and the correct understanding of some pieces combined with the incorrect understanding of others, led to the decision to fire the missiles. The cues that were consistent with a hostile aircraft preparing to attack were several. However, the situation was not entirely consistent with an attack. Hindsight shows that Capt. Rogers was terribly wrong in his assumptions, and it also shows that the USS Sides, viewing the same picture on the AEGIS command and control system, concluded that the aircraft was indeed a commercial airliner. The official U.S. Navy analysis, the Fogarty Report, concluded that, "stress, task fixation, [and] an unconscious distortion of data may have played a major role in the incident. [A crew member] ap-

\footnotetext{
${ }^{38}$ Klein, Sources of Power, 76.

${ }^{39}$ Klein, Sources of Power, 79.
} 
pear[ed] to have distorted data flow in an unconscious attempt to make available evidence fit a preconceived scenario." 40

This way the incident could be explained as human error caused by a bias in trying to explain away inconvenient information. Other explanations of this event in other studies bring the expectancy bias into play as well, in that the crew was likely to see what they expected to see. ${ }^{41}$

Hindsight is useful in condemning the tragic decision. If Capt. Rogers had not decided to fire the missiles, and the aircraft had in fact turned out to be an F-14, that would also have been a serious mistake, and could be explained as a clear case of bias, but this time the bias would have been to ignore the base rates, to ignore the expectancies. The conclusion is that both cases could be explained by human error as a result of biased decisions. Klein argues that the decision bias approach explains too much: "If you act on expectancies and you are wrong, you are guilty of expectancy bias. If you ignore expectancies and are wrong, you are guilty of ignoring base rates and expectancies." 42

Klein argues that, with hindsight, every error can be explained by decision bias, but that this does not tell us much about the reasons why the control room in the USS Vincennes was not able to come up with the right decision. Another study of the incident concluded that a system error was responsible, in that the correct pieces of available information were not displayed, which, according to Klein, in fact was the reason that prevented the crew from comprehending and recognizing the situation in the right context in the first place. ${ }^{43}$ Today, the operation rooms in AEGIS cruisers have been modified. This is largely due to Klein's research into the area, and the result is an improved interface between human and machine, based on an understanding of how decisions are actually made.

In the British military, command is intrinsically linked to decision-making. The British Military Doctrine (BMD) states that the "exercise of command is primarily concerned with the decision making process." making, and control is also referred to as the aspects of command. ${ }^{45}$ The doctrine further emphasizes that it requires "good judgment and initiative" to know when a decision is needed. ${ }^{46}$ The British Defense Doctrine emphasizes the importance of efficient and timely decision-making: "A key characteristic of the Manoeuvrist Approach is the attacking of the enemy's commander's decision-making process by attempting to get inside his decision-making cycle, thus achieving a superior operational tempo."

\footnotetext{
${ }^{40}$ Klein, Sources of Power, 83-84.

${ }^{41}$ Klein, Sources of Power, 84.

${ }^{42}$ Klein, Sources of Power, 85.

${ }^{43}$ Klein, Sources of Power, 87; and Klein, "Strategies of Decision Making," Military Review (May 1989): 56-64.

${ }^{44}$ British Military Doctrine, 4-17.

${ }^{45}$ Command, 1-4, para. 0110.

${ }^{46}$ Command, 2-9.

${ }^{47}$ JWP 0-01 British Defense Doctrine, $2^{\text {nd }}$ ed., 3-5.
} 
Operational decision-making lies at the heart of military command, and military organizations like the British military have developed strategies to cope with the difficulties inherent in the process. This includes an analytical process that is taught in peacetime to increase predictability and accountability, while recognizing that military success in war has often depended upon the commander's perception, intuition, and creativity for proper judgment.

The dynamics of decision-making can be explained by referring to the Boyd Cycle, or the Observe, Orient, Decide, Act (OODA) loop. ${ }^{48}$ The "Manoeuvrist Approach" to war fighting, as quoted above, is to a large extent focused on getting inside the enemy's decision cycle. Technical improvements have over the years been a major factor in achieving this objective. Improved Observation capabilities, fed into a capable command and control system, will enable greater situational awareness. This will then allow faster Orientation through additional processing of the data, and faster Decisionmaking. The result is faster and more decisive Action through the application of force.

Looking into the future, it becomes reasonable to assume that the slowest part of the OODA loop soon will be the commander's ability to take in and process all available information. The problem was experienced already by the U.S. chain of command in Vietnam. Lessons learned after the war highlight that more information does not necessarily mean more understanding - in fact, the opposite is often the case. ${ }^{49}$

In order to decide on a course of action, a commander needs information. Clausewitz claimed that "[A] great part of the information obtained in War is contradictory, a still greater part is false, and by far the greatest part is of a doubtful character." ${ }^{50}$ Martin Van Creveld argues that the nature of war brings to the fore some of the strongest emotions known to man when independent wills are confronting each other, and thus reduces the possibility for certainty to a minimum. ${ }^{51}$ Schmidt and Klein conclude that increased information access increases complexity of decision-making. They argue that "information is dramatically non-linear; that is, all pieces of information do not have nearly the same value or influence." 52

Van Creveld describes the essence of command as the ability to deal successfully with uncertainty, to function effectively in the absence of complete information. ${ }^{53}$ However, information must be made available to make decisions, but the more available information there is, the longer the time needed to process it. Training and experience are important factors in situational awareness, but ultimately, as Van Creveld states, command relies "no less on intuitive judgment than on rational calculation.",54

${ }^{48}$ Command, 3-6, para. 0313.

${ }^{49}$ Martin Van Creveld, Command in War (Cambridge, MA: Harvard University Press, 1985), Chapter 7.

${ }^{50}$ Carl von Clausewitz, On War, ed. Col. F.N. Maude (London: Penguin Books Ltd, 1982), 162.

${ }^{51}$ Van Creveld, Command in War, 266.

52 J.F. Schmidt and G. Klein, "Fighting in the Fog: Dealing with Battlefield Uncertainty," Marine Corps Gazette 80:10 (1996): 63-66.

${ }^{53}$ Van Creveld, Command in War, 268-75.

${ }^{54}$ Van Creveld, Command in War, 267. 


\section{Moltke seems to have supported a similar view:}

The problem is to grasp in innumerable special cases, the actual situation which is covered by the mist of uncertainty, to appraise the facts correctly and to guess the unknown elements, to reach a decision quickly and then to carry it out forcefully and relentlessly. ... It is obvious that theoretical knowledge will not suffice, but that here the qualities of mind and character come to a free, practical and artistic expression, although schooled by military training and led by experience from military history or from life itself. ${ }^{55}$

Van Creveld argues that command can be viewed as both an organizational function and a cognitive function, and that technology by itself is not a panacea. This is worth considering as command and control systems become more and more advanced, and the human interface is a daily concern. In a confused situation, a commander needs what Clausewitz described as "... the rapid discovery of a truth which to the ordinary mind is either not visible at all or only becomes so after long examination or study.",56 A commander must have the courage to follow a rapid recognition like the one Clausewitz describes, and the question arises: Does the military teach its leaders to become self-reliant in this respect?

According to Thomas Czerwinski, we stand at a crossroads with regard to command and control. ${ }^{57}$ One road is marked "Technology" and the other "Art." The way forward must be plotted out for us by the forward projection of doctrine, constantly updated, to reflect both requirements and improvements in understanding. The question is which way to choose, and whether or not the military will be able to change its focus from the technology and digitalization of the command and control system, and rely more on "art."

The use of modern information technology channels the development of intelligence to cope with the vast increase in the complexity of information and the speed at which it must be handled. The ability to take time to ruminate and contemplate, which may be required to deal with confusion and uncertainty, is becoming outdated. The computer in the command and control system cannot deal with confusion, not unless it has been clearly articulated at the most basic level by the information handler. The danger is that subtler meanings might get lost during the process of articulating it into something that "computes." 58 The computer does not keep vague ideas on the back burner of its memory, suddenly to appear again, more refined, in a way the intuitive mind might experience.

The science of decision-making seeks certainty, rationality, and logic. It is articulate and analytic, dividing the problem into individual components that could be an-

${ }^{55}$ Helmuth Karl von Moltke, quoted in E.M. Earle, The Makers of Modern Strategy: Military Thought from Machiavelli to Hitler (Princeton, NJ: Princeton University Press, 1944), 179.

${ }^{56}$ Clausewitz, On War, 142.

${ }^{57}$ Thomas J. Czerwinski, "Command and Control at the Crossroads," Parameters (Autumn 1996):121-33.

${ }^{58}$ Claxton, Hare Brain, 206-7. 
swered yes or no, like algorithms in computer language. In British military planning, the Command Estimate is the preferred analytical tool. The decisions produced by this process are accountable, understandable, and predictable. All aspects of a problem are analyzed before a decision is made. The influence of human factors is reduced to a minimum to avoid errors from bias or prejudice. However, the process still encourages the application of intuition and creativity in the development of courses of action for both oneself and the enemy. This twist to the analytical tool is worth bearing in mind, and will be commented upon later.

Col. Rogers argued that, "intuition reflects the art rather than the science in command." Making decisions by following intuition represent the opposite of the analytical approach, in that it lets a number of unexplained and unaccounted factors influence the process. These decisions are often high-risk, unpredictable, and incomprehensible to others, and sometimes to the decision-maker as well. It is difficult to decide if they are the result of genius or intellectual carelessness if the means to formally assess them are not in place. $^{59}$

Rational analytical decision-making is generally the preferred model in most military organizations for dealing with complex multi-level problems: "From Plato to NATO, the history of command in war consists of an endless quest for certainty ... about the state and intention of the enemy ... about the environment ... and about ... one's own forces." ${ }^{60}$ According to Van Creveld, two factors are essential in the quest for certainty: "the amount of information available for decision-making and the nature of the task to be performed." ${ }^{\prime 61}$ Van Creveld draws the conclusion that the tasks necessary to win battles in the future will become increasingly complex to perform, as the battlefield becomes more sophisticated. The result is a lower degree of certainty in the outcome. Improvements in information availability are counterbalanced by the increased difficulty in the exploitation of the same information.

There are two elements that present obstacles to certainty, according to Van Creveld: nature and logic. In order to be truly logical, all information relevant to a decision must be obtained in order to achieve certainty. This leads to a paradox in that, the more information that is gathered, the longer it will take to process it. The result is a more confused situation, where it becomes difficult to separate the important, relevant, and reliable pieces of information from the unimportant, irrelevant, and unreliable ones. ${ }^{62}$ War is a human activity where strong independent wills are pitted against each other; that fact, together with strong emotions, adds to the level of uncertainty.

\footnotetext{
${ }^{59}$ Rogers, "Intuition," 38-50.

${ }^{60}$ Van Creveld, Command in War, 264.

${ }^{61}$ Van Creveld, Command in War, 265.

${ }^{62}$ Van Creveld, Command in War, 267.
} 
The classic analytical decision-making models demand that all relevant information be obtained to gain full situational awareness before reaching a decision. ${ }^{63}$

The way decisions are made has been the object of a large number of studies, and today one talks, in a broad sense, about the rational analytical decision-making models and the naturalistic decision-making models. These models are the basis for the study of decision-making in the British military. ${ }^{64}$

The rational analytical models have their strengths in breaking down and analyzing complex problems in their individual parts, before the results are synthesized and options are compared to each other to find, if possible, the best solution. One advantage of this method is that relatively inexperienced staff, following a procedure like the sixstep estimate, can arrive at the same decision as would more senior officers. The result is possible to justify, since the process can be documented relatively easily. In a military environment, the requirement for justification is needed in most circumstances, and definitely if time permits. It is difficult imagining an acquisition program developing and at the same time being able to justify a set of conclusions without following a rational analytical decision making model. However, the decision-making environment in peacetime, compared to times of tension or conflict, can be fundamentally different, and the model that works best during wartime may not be the most appropriate one to use during peacetime.

Rational analysis is a specialized and potent "Source of Power," according to Klein. Analysis is a tool used to make fine discriminations when confronted with multifaceted and novel problems requiring the calculation of noisy data to find trends. It is valuable in a broad search for many options, and reduces the chance that an important option will be overlooked. Rational analysis has been key in the development of technology and science. ${ }^{65}$

Analytical decision-making is a rational process, systematically undertaken in a linear way, comparing multiple options concurrently. The outcome of the process, which is also known as multi-attribute utility analysis, is the optimal solution to the problem. This is the theoretical basis for the estimate process, ${ }^{66}$ and it is the approved military decision-making tool in the British military.

However, the process of analysis, as conducted in the estimate, also includes additional elements other than pure rational analysis:

${ }^{63}$ One definition of situational awareness is the "continuous extraction of environmental information, integration of this information with previous knowledge to form a coherent mental picture, and the use of that picture in directing further perception and anticipating future events." C. Dominguez, "Can SA Be Defined?" in Situational Awareness: Papers and Annotated Bibliography (Armstrong Laboratory, Wright-Patterson AFB, OH, 1994), 7; available at http://www.raes-hfg.com/crm/reports/sa-defus.pdf (accessed 19 March 2004).

${ }^{64}$ Essential Reader, ACSC 7, Decision Making and Military Planning, Part 1A, Sep 03-Jul 04.

${ }^{65}$ Klein, Sources of Power, 260-61.

${ }^{66}$ J. Hwang and D. Schutzer, Selected Analytical Concepts in Command and Control (New York: Gordon and Breach Science Publishers, 1982), Section 1, 3-33. 
During the identification and assessment of courses of action one needs to use creative, conceptual and synthesizing processes to draw up the courses of action, as the various concepts of operation are more than the sum of all the tasks and constraints accumulated during the Estimate. That having been done, one uses rational, deductive, analytical processes to assess them. ${ }^{67}$

Within the model, analysis is used first, then conceptualizing, and then analysis again. To facilitate this process, the estimate process has been divided into steps that keep the expert - the commander - in the loop to conceptualize, spending time thinking about possible courses of action, leaving the handling and processing of information to the staff. Hopefully, the commander can apply intuition to the process at this stage, as the doctrine suggests.

During the analysis of factors in the rational analysis model, questions like "so what" or "if-then" are used to come to the ultimate deduction or basic decision component for a specific factor. The problem in a complex or ambiguous context is that it is hard to say if the antecedent condition has been met. In the laboratory, researchers prefer context-free artificial problems to help eliminate ambiguity. In the military context, following the "Manoeuvrist Approach" to operations, it is especially important to understand the intent behind a certain rule or order, and that may help us in determining the answer to the "so what" question in a particular complex context, where it is not possible to deduce every possibility. ${ }^{68}$

However, the estimate requires information to be articulated before it can be processed. This is not always possible for the subtler pieces of information, at least not without some of the meaning being lost, and it can be a slow undertaking. Hence the estimate does not necessarily support the potential for high-tempo warfare, as the decision is not reached until the end of the analytical process. The fact that situational awareness also demands a holistic component is another drawback with the estimate, as this is not produced until the gathered information is synthesized.

Training in the estimate focuses on process rather than product, and therefore this could lead to a cultural mindset suggesting that, when the process is mastered, the correct answer will be reached. However, on the other hand, it is often said that there is no such thing as a 'right' answer to tactical problems. During training in the estimate, it is emphasized that the process is not conclusive, and that understanding the weaknesses of the method is an important prerequisite for using it successfully. However, for decision-makers faced with simple problems that offer few alternative courses of action, and when there is room for searching out and evaluating the alternatives, the rational analytical decision-making model represents a fairly accurate description of the decision process. ${ }^{69}$

${ }^{67}$ Essential Reader, ACSC 7, 2.

${ }^{68}$ Klein, Sources of Power, 263.

${ }^{69}$ D.L. Rados, "Selection and Evaluation of Alternatives in Repetitive Decision Making," Administrative Science Quarterly (June 1972): 196-206. 
The naturalistic decision-making model is another approach to decision-making. This theory focuses on understanding how people think naturally, and the ability to observe the setting or context of any given situation is the core building block of this method. Both the quality and timeliness of the decision-making process can be improved by understanding how people think, as opposed to the analytical method, which focuses on instructing people how to think. Gary Klein is the leading expert in the field of naturalistic decision-making studies, and has examined experienced decision-makers in contexts of time pressure, inadequate information, dynamic situations with poorly defined procedures, and poorly defined or competing goals. When dealing with experienced decision-makers, the situation will often also involve high stakes. Klein refers to the ways people think and decide in a natural setting that helps them in the decision process as "Sources of Power." 70

Recognition primed decision-making builds on the ability to recognize a given situation as being similar to past experience. As new information is processed, the decision-maker will develop situational awareness incrementally. The working memory is then used to look into the future, based on possible solutions. When a solution is found, it is selected. The cognitive process of making a decision is incremental and intuitive. Recognition primed decision-making uses the concept known as "satisficing." 71

Recognition primed decision-making is about choosing the first option that works, and not about optimizing the outcome. This way of thinking is linked to the research of Herbert Simon, who identified a strategy for decision-making that he called "satisficing," which means developing options based on experience and recognition before choosing the first option that satisfies the need for a decision in a particular situation. Optimizing, which is the goal in the rational analytical model, is difficult and takes a long time, while satisficing is more effective. Under immense time pressure, satisficing makes more sense. $^{72}$

The recognition primed model works for experienced personnel in that they are able to assess a situation and judge it familiar, quickly choosing a solution that works, rather than comparing options. Experienced decision-makers concentrate on understanding the situation, whereas the inexperienced decision-maker tends to focus on the selection of the correct response. Courses of action are quickly evaluated by imagining how they will be carried out, instead of by formal analysis and comparison. Usually, experienced decision-makers look for the first workable option they can find and not the best option. Often the first option the experienced decision-maker considers is workable, and he or she does not have to consider a large set of options. The options are generated one at a time, and the decision-maker does not spend time comparing the relative advantages and disadvantages of alternatives. Imagining the option being carried out helps the decision-maker to spot weaknesses in it and find ways to avoid these,

\footnotetext{
${ }^{70}$ Klein, Sources of Power, 4-6.

${ }^{71}$ Gyllensporre, "Decision Navigation," 27.

${ }^{72}$ Klein, Sources of Power, 20. Gyllensporre, "Decision Navigation," 27.
} 
thereby constantly improving the option. This can be a serious advantage over the conventional model of decision-making, which selects the best option after having compared courses of action, thereby placing less emphasis on the possibility of improving the various options. By using the recognition primed decision-making model, the focus is placed on being poised to act as soon as possible, rather than being paralyzed until all the evaluations have been completed. ${ }^{73}$ Capt. Rogers on the USS Vincennes relied on an ability to imagine what the opponent was thinking, and recognizing the situation from past experience.

Using recognition primed models does not mean that multiple options are not developed, but that they are developed sequentially rather then concurrently, as in the rational analytical models. The recognition primed model emphasizes achieving situational awareness and assessing of the situation over selecting among evaluated options. The situation must therefore be possible to link to recognizable, concrete experience, and not largely dependent on abstract data. Justification of decisions will be difficult in retrospect, and the method suffers from weaknesses in cases where competing interests needs to be evaluated. Campaign planning, or the planning of complex acquisition programs with high complexity in several dimensions, will be difficult to undertake using the recognition primed decision-making model.

The ways in which decisions are made in reality often do not strictly follow a particular model, but instead rely on a combination of several models. Very often individuals make decisions by constructing simplified models of the problem that extract the problem's essential features without capturing all their complexity. This has been studied in the world of politics, but is also a common feature of decisions in everyday life. Bounded rationality will most often lead to decisions that are "good enough." Once the decision-maker has identified a number of criteria, and listed a number of alternatives, the reviews of the alternatives begin. The list might be far from exhaustive. When the first alternative that is "good enough" is reached, the decision is made. It is important to note here that the order in which the alternatives are reviewed is critical in reaching a particular decision. There might be several alternatives that are "good enough," and the order in which they are examined might then determine which one will be selected. $^{74}$

Intuitive decision-making can be described as "an unconscious process created out of distilled experience." ${ }^{, 75}$ It has been claimed that intuition is a natural gift that is simply more predominant in some people, while others, like Agor and Claxton, support the view that intuition can be developed. ${ }^{76}$ However, teaching on the subject in military establishments is virtually non-existent. It is as though the technological fixation within the military in the past several decades has led to a diminished understanding and

${ }^{73}$ Klein, Sources of Power, 30.

74 Robbins, Organizational Behavior (2001), 136.

${ }^{75}$ Robbins Organizational Behavior (2001), 137.

${ }^{76}$ W.H. Agor, Intuition in Organizations (Newbury Park, CA: Sage Publications, 1978); Claxton, Hare Brain. 
valuing of human characteristics. It has been argued that encouraging the proper understanding and development of intuitive ability is long overdue in the military system. ${ }^{77}$

Intuitive decision-making is not necessarily an independent process from rational decision-making, but rather a complement to it. In the military estimate process there is room for the commander to make use of his intuition but, as was mentioned earlier, this might be a difficult task to combine with the rational analytical process, and one that requires relevant training in and understanding of how the deeper mind works. To a large extent the use of intuition, as opposed to the analytical approach, is culturally dependent. In North America and Great Britain the rational analytical method is the approved way of making decisions. Other cultures might have completely different methods of collecting and valuing information, selecting problems, and analyzing in depth, and may place different levels of importance upon logic and rationality. "Through lack of imagination or circumspection we may easily miss possible courses of action," Adair writes. "Our minds have a tendency to dichotomize, i.e., to see reality in terms of either/or, and we carry this bias with us into the decision-making situation." ${ }^{, 79}$ This is often a characteristic difference between Western and Asian cultures.

Today there is an ever-growing recognition that rational analysis has been overemphasized in the past. Relying more on intuition can in many ways improve the decisionmaking process; it is no longer automatically assumed by experts that using intuition is irrational or ineffective. ${ }^{80}$ To get a better understanding of how intuition really works, it is necessary to look into the functioning of the deeper mind.

Analytical decision-making might, simply put, be thinking too hard sometimes. "The spirit of decision analysis is divide and conquer," Raiffa writes: "decompose a complex problem into simpler problems, get your thinking straight in these simpler problems, paste these analyses together with a logical glue and come out with a program for the complex problem." 81 This could be a relatively good argument for the military estimate process. The theory is that if one can be as explicit, articulate, and systematic as possible, the best decisions and solutions will be generated. However, in some situations when decisions have to be made it can be quite complicated to be very reflective and explicit about the factors on which it is necessary to base a decision. There might be many interwoven considerations to take into account, some of which may be hard to articulate. Some research shows that in an analytical approach to decision-making, these considerations might be given less weight than if the decisions were

${ }^{77}$ Brigadier G.L. Kerr, "Intuitive Decision-Making at the Operational Level of Command," British Army Review 108 (1994): 5-13.

${ }^{78}$ Robbins, Organizational Behavior (2001), 143.

79 J. Adair, Training for Decisions (Aldershot: Gower Publishing Company Ltd., 1971), 57.

${ }^{80}$ Robbins, Organizational Behavior (2001), 137; W.H. Agor, ed., Intuition in Organizations (Newbury Park, CA: Sage Publications, 1989); O. Behling and N.L. Eckel, "Making Sense out of Intuition," Academy of Management Executive (February 1991): 46-47; Klein, Sources of Power; P.E. Ross, "Flash of Genius," Forbes, 16 November 1998, 98-104.

${ }^{81}$ H. Raiffa, Decision Analysis: Introductory Lectures on Choices under Uncertainty, (Reading, MA: Addison Wesley, 1968), 271. 
made in an intuitive way. ${ }^{82}$ When forcing an analytical decision-making model on a complex problem, the problem has to be deconstructed into considerations that are possible to put into words. In consciousness, this predicament may be a distortion to some degree of the way the problem is tacitly first understood. Decisions based on this articulated analysis might therefore not be fully satisfactory. ${ }^{83}$ However, analytical reasoning is essential in the multi-faceted process of decision-making. A clear and explicit grasp of situations is necessary in military command, where there is a need for communicating to other people. The ability to articulate one's own ideas is paramount in good and precise communication. Further, the ideas spat out from the unconscious by intuition and creativity must be tested and refined. There is the need both to generate ideas by intuition and to evaluate them by analysis: "It is by logic we prove; it is by intuition we discover." 84

To further understand the factors influencing decision-making, it is now time to look at how the mind works according to cognitive science. In particular, we will examine the connection between consciousness, unconsciousness, and the deeper mind. Guy Claxton refers to three different processing speeds of the mind. The first is what he calls the "wits" that help us make a corrective movement when we miss a step on the stairs, and thus perhaps prevent us from falling. It is faster than thought, and is more like a reflex action. The second process is the deliberate, conscious thinking that relies on reason and logic, often called "intellect." The third mode of our mind is the contemplative or meditative state; a more patient, less deliberate mode of mind particularly suited for making sense of situations that are intricate, shadowy, or ill defined. According to recent scientific evidence, this third mode is the realm of mind beyond and beneath the conscious intellect. Claxton claims that well-known creative scientists, like Albert Einstein, admitted that their genius came from layers of mind over which they had little or no control. ${ }^{85}$ Several other authors have suggested that some people seem to have gained access to resources within their mind that give them more ability than others. Clausewitz described intuition as "Coup d'oeil," "the rapid discovery of a truth which to the ordinary mind is either not visible at all or only becomes so after long examination or study." ${ }^{\text {" Na }}$ Napoleon talked about "a superior understanding," and engaged in meditative thinking before entering battle, and (perhaps as a result) often appeared to have luck on his side:

If I always appear prepared, it is because before entering on an undertaking, I have meditated for long and have foreseen what may occur. It is not genius that reveals to

\footnotetext{
${ }^{82}$ Based on studies conducted by Jonathan Scholer at the Learning Research and Development Center at the University of Pittsburgh; presented in Claxton, Hare Brain, 86-90.

${ }^{83}$ Claxton, Hare Brain, 87.

${ }^{84}$ Henri Poincaré, quoted in Claxton, Hare Brain, 93.

${ }^{85}$ Claxton, Hare Brain, 3.

${ }^{86}$ Clausewitz, On War, 142.
} 
me suddenly and secretly what I should do in circumstances unexpected by others, it is thought and meditation. ${ }^{87}$

Fuller observed, "like the great artist, the general should possess genius, and if he does not, then no effort should be spared to develop his natural abilities in place of suppressing them." ${ }^{\prime 8}$ The need to develop leaders' natural abilities has arguably not been sufficiently addressed during the past decades in the military. There might be a need for a renewed focus on how the military thinks about learning. The aim might be to also cover the tools and knowledge that could potentially make a military commander more resourceful, so that he or she will be better able to deal with uncertainty. The power of intuition as an essential complement to reason when dealing with complicated situations can certainly be valued more in military training. ${ }^{89}$

Claxton calls the third mode the slow way of knowing, because the undermind needs time. This might then render it useless in dealing with the outputs of the highspeed information highway that runs through military command and control systems. However, many of the complex problems that face the commander on the battlefield are not entirely new and unique. There might still be room to do as Napoleon did before battle - meditate in advance. Major-General N. R. Parker, CO JSCSC, said about military leaders in general that too little time is spent reflecting on their own leadership and that of others. ${ }^{90}$

Knowledge of the profession is essential for any military commander in the decision-making process. In addition to formal education and training, knowledge is improved through research, thought, and reflection on the theory and practice of war. The commander must have an understanding of the flexible application of doctrine to the context of the situation he or she is in. ${ }^{91}$ Experiments show that people who have been instructed fall back on the rational analysis mode when pressured, while those who have not been taught a specific body of knowledge continue based on what they had learned intuitively. ${ }^{92}$ Following on the previous discussion about bias, this might indicate a bias to resort to the rational analytical model if that is the only fallback option. This might tell us that there is room for changing our approach to learning, and that the complex multi-faceted process of decision-making should be looked at from different angles.

The possible effects of pre-existing conscious beliefs have already been described during the discussion on human error. Experiments performed by Pawel Lewick show,

${ }^{87}$ Napoleon Bonaparte, quoted in Robert Heinl, Dictionary of Military and Naval Quotations (Annapolis, MD: Naval Institute Press, 1966).

${ }^{88}$ Maj. Gen. J.F.C. Fuller, Generalship: Its Diseases and their Cure: A Study of the Personal Factor in Command (Harrisburg, PA: Military Service Publishing Co., 1936), 87.

${ }^{89}$ Claxton, Hare Brain, 11.

${ }^{90}$ Maj. Gen. N.R. Parker, remarks during introduction to lecture on leadership by Sir Robert Walmsley at JSCSC/ACSC7, 16 March 2004.

${ }^{91}$ Army Doctrine Publication Vol. 2, Command (1995), 2-18.

${ }^{92}$ Claxton, Hare Brain, 39. 
according to Claxton, that pre-existing conscious beliefs did not have any "effect on the speed or efficiency with which the contrary associations were learnt through experience; and were themselves unaffected by the conscious learning that had taken place. The undermind is acquiring knowledge of which consciousness is unaware, and by which it is unchanged, and using it to influence the way people behave." 93 Therefore there "develops a difference or schism between what people think they know about themselves, and the information that is unconsciously driving their perception and reaction." This should indicate that there is a second center that is capable of going its own way, apart from the conscious mind. Lewick concludes, "Our non-conscious information processing system appears to be faster and smarter overall than our ability to think and identify meaning in a consciously controlled manner. Most of the 'real work' of the mind is being done at a level to which our consciousness has no access." 94 This opens up another perspective on understanding the workings of the mind, and it may be appropriate here to refer to Clausewitz, who noted that the essence of military genius is to bring under consideration all of the tendencies "of the powers of the mind and soul towards the business of war." 95

To conclude, it is time to absorb the findings of new research in cognitive science, use this research to justify a shift in the military learning curriculum, and add new knowledge to the traditional rational analytical approach to decision-making that is dominant in Western militaries. The future battlefield requires it, as the human in the Observe Orient Decide Action loop soon will become the weak link. Cognitive science can add to our understanding of the human mind and its capabilities. It is no longer necessary to accept the Cartesian premise that consciousness is intelligent and controlled, thereby indicating that the unconscious must be emotional, irrational, wild, and alien. ${ }^{96}$ The power of the unconscious intelligence needs to be given a more prominent position among the pool of resources from which the military commander draws in his decision-making strategies.

The OODA loop builds on the theory that, in the midst of battle, a person continuously moves through a recognitional decision pattern. The commanders who manage to cycle through the loop faster than their enemies make decisions more rapidly, and thus gain an advantage. Looking toward the future, it becomes reasonable to assume that the slowest part of the OODA loop soon will be the commander's ability to take in and process all available information. According to Krulak, the chief advantage of intuitive decision-making is its speed: "History has repeatedly demonstrated that battles have been lost more often by a leader's failure to make a decision than by his making a poor one." 97 This might then push us towards accepting unnecessary risk, by encouraging the human factor of intuition to dominate over the rational analytical method, and

${ }^{93}$ Claxton, Hare Brain, 37-38.

94 Pawel Lewick, quoted in Claxton, Hare Brain, 38.

${ }^{95}$ Clausewitz, On War, 138.

${ }^{96}$ Claxton, Hare Brain, 223-24.

${ }^{97}$ Krulak, "Cultivating Intuitive Decision-making," 18-22. 
therefore increasing the likelihood of human error. Klein argues, however, that bias in decision-making might be overestimated as a factor in making people predisposed to make poor decisions. Further, he asserts that the decision bias argument comes from experiments run under artificial laboratory conditions, and that judgment bias has a very small impact outside laboratory conditions. ${ }^{98}$ Maybe it is time to put more trust in the human mind than we have traditionally been willing to do.

Klein's research indicates that people most commonly use the recognitional, or intuitive, model of decision-making. Analytical decision-making uses a scientific quantitative approach that depends upon high levels of accuracy and certainty about the situation in order to be effective. Besides, it can be a time-consuming process, requiring the handling and analysis of all available data. War is the result of two opposing wills, an encounter that is chaotic and emotional by nature, thereby creating what Clausewitz called "the fog of war," and resulting in a high level of uncertainty. Van Creveld supports the idea of uncertainty as an intrinsic element of the nature of war, and asserts that technological or scientific solutions will not be adequate to solve the problem of uncertainty or process all the available information.

The military focus on the analytical model for decision-making in the attempt to avoid human error does not contribute to efforts to lift the "fog of war." Command and control systems and doctrine are designed to remove possible sources of error by disassociating man's cognitive abilities from the process. This is, however, not always a path to success, as it might also remove sources of doubt or feel for the situation. Once the enemy is engaged, military situations tend to become very ambiguous, and the military commander does not have enough time to wait for all the detailed quantitative data to be analyzed without risking losing the initiative. As Krulak notes, "The analytical model does not lend itself well to military applications once the enemy is engaged." G99 Good analysis and good outcomes are not synonymous; "The former means the problem has been diagnosed correctly, but this analysis doesn't automatically produce good results."

Most military decisions will be driven by uncertainty and time, and intuitive decision-making should become the norm rather than the exception. By valuing experienced judgment and intuition over the analytical approach, tempo and flexibility become tools with which to manage uncertainty. However, when time is not a critical factor, the military commander must be able to adopt an analytical approach that will reinforce intuitive decision-making. Essential in decision-making, especially to achieve success in warfare, is a style that supports "boldness," and includes calculated risktaking and originality. Furthermore, this decision-making method must also accommodate "timeliness," in that mission command requires tempo to outmaneuver the enemy through a more rapid decision-action cycle. ${ }^{101}$ This supports the intuitive approach to

\footnotetext{
${ }^{98}$ Klein, "Strategies of Decision Making," 56-64.

99 Krulak, "Cultivating Intuitive Decision-making," 18-22.

100 R. Rowan, The Intuitive Manager (Boston: Little, Brown \& Co., 1986), 104.

101 Army Doctrine Publication, Vol. 2, Command, 2-24.
} 
decision-making as the model that would best meet the needs of the modern military commander.

Napoleon talked about the need for meditation, and about intuition, which he thought was a gift. He might have been right when he thought that intuition could not be taught in the traditional sense, but both past and current research has showed that it can be learned. The question is one of how the military can cultivate intuition. Krulak argues that this must be done under circumstances that favor and encourage intuitive decision-making. There is a need to literally inculcate a "culture" of intuitive decisionmaking. Self-study, learning, and reflection are important, but most important is asking the right questions about one's own leadership and that of others. ${ }^{102}$ Claxton supports this idea, and argues that, first, there is a need to create the right learning climate that values the mental modes that nurture intuition. Second, there is a need for leadership that values and encourages new ideas and judges them by merit rather than by how slickly and persuasively they are put across.

Empirical research in cognitive science can add to our knowledge of the mind and help us push for a shift in the understanding of its capabilities, but the most important lesson it can teach us is to trust the unique capabilities of intuition and creativity. These give the military commander mental tools more suited for the intricate tasks that will confront him or her on the battlefield. It might give a leader the ability to be innovative and to understand the situation, making a judgment based on a snippet of information, seeing through the fog, rather than waiting for it to clear.

${ }^{102}$ Krulak, "Cultivating Intuitive Decision-making," 18-22. 
VOL. III, NO 2, JUNE 2004

\section{Bibliography}

Claxton, Guy. Hare Brain Tortoise Mind . London: Fourth Estate, 1998.

Czerwinski, Thomas J.. "Command and Control at the Crossroads." Parameters (1996).

Hammond, J.S., R.L. Keeney, and H. Raiffa. "The Hidden Traps in Decision Making." Harvard Business Review (1998).

Hwang, J., and D. Schutzer. Selected Analytical Concepts in Command and Control . New York: Gordon and Breach Science Publishers, 1982.

Klein, Gary A.. Sources of Power: How People Make Decisions . Cambridge, MA: The MIT Press, 1998, 1998.

Krulak, Gen. C. C.. "Cultivating Intuitive Decision-making." Marine Corps Gazette (1999).

Mintzberg, Henry. "The Rise and Fall of Strategic Planning." New York, NY: The Free Press (1994).

Rados, D.L.. "Selection and Evaluation of Alternatives in Repetitive Decision Making." Administrative Science Quarterly (1972).

Robbins, S.P.. Organizational Behavior: Concepts, Controversies, and Applications. Engle-wood Cliffs, NJ: Prentice-Hall, 1993.

Rogers, Col. C. T.. "Intuition: An Imperative of Command." Military Review (1994).

Schmidt, J.F., and G. Klein. "Fighting in the Fog: Dealing with Battlefield Uncertainty." Marine Corps Gazette 80, no. 10 (1996).

Tversky, A., and K. Kahneman. Judgment under Uncertainty: Heuristics and Biases In Science., 1974.

Van Creveld, Martin. Command in War. Cambridge, MA: Harvard University Press, 1985. 